\title{
An Analysis of Future Coaches' Emerging Dispositions on Social Justice: The Wooden Effect
}

\author{
Brian Culp \\ Department of Kinesiology, Indiana University Purdue University \\ Indianapolis, 901 West New York Street, Indianapolis, \\ Indiana 46202-5193, USA \\ E-mail: briculp@iupui.edu
}

\begin{abstract}
This qualitative study explored the extent to which an archetype presented through a non-fiction text could impact aspiring coaches' (AC's) dispositions regarding social justice. Forty-three aspiring coaches at a Midwestern university enrolled in a foundations class that presented issues related to inequity were studied. Analysis of student journals indicated changes in AC's philosophies regarding social justice, an appreciation for the perspectives of underrepresented groups and emergent critical perspectives when examining sport processes. Results of the study imply that a focus on democratic education and constructivism in coaching preparation programs may be of benefit. A means by which praxis of this nature can be realized for future professionals is presented using Giddens' structuration theory.
\end{abstract}

Key words: Archetypes, Coaching Education, Critical Pedagogy, Democratic Education, Diversity, Sport Literature

\section{INTRODUCTION}

One question that has not been answered sufficiently is how to develop mindsets in future coaches that will contribute to positive change. In recent years, social justice has been introduced as a means to afford full and equal participation in a society for marginalized and systematically oppressed groups. Through this framework, leaders are social actors who have a sense of their own agency while understanding their responsibility toward and with others in the broader world in which we live [1].

Coaches are leaders. They have occupational roles and demands that place them in positions to be social actors who provide a benefit. This includes contact with a wide range of individuals, skill instruction that can be differentiated, physical movement, public evaluation and accountability, contact with clients, motivation, and adapting to changing environments [2]. While social justice education has been postulated as a viable solution for challenging inequality [7], what is not known is how future coaches are trained to act as these situations arise. As such, attention to this issue is warranted in order to effectively promote sport participation that is inclusive for all. 
This article presents a qualitative study of aspiring coaches enrolled in a foundations course where John Wooden was used as an archetype for social justice. After defining archetypes, the role of democratic education in teaching for social justice will be discussed. Then, findings highlighting student observations and critical thinking on issues presented in the foundations course will precede recommendations on how social justice could be taught in pre-professional settings.

\section{JOHN WOODEN AS ARCHETYPE}

Carl Jung believed that archetypes were universally understood symbols, models of people, behaviors or personalities that form in the collective unconscious. Mayes [3] provides a modern definition that incorporates instruction, espousing that archetypes stem from universal dispositions that inform, organize and direct the actions of humans.

Archetypes are represented in forms such as philosopher, judge, parent, counselor, or master teacher. Mayes notes that master teachers are distinctive. They care about the emotional states, spiritual dispositions, situations, and processes that impact the people they lead. Further, they are genuine in their concern for those who look to them for guidance, insight and awakening.

Wooden is a distinctive basketball luminary. Substantive commentaries highlight his acumen, motivational techniques and ability to teach. In leading his teams to 10 National Basketball Men's Championships at the University of California, Los Angeles (UCLA), Wooden felt his success came as a result of adhering to core principles taught to him in his upbringing. These principles, along with his philosophy and maxims left a legacy that transcends the world of sport.

Throughout his career, Wooden promoted equity and the implementation of justice through civil rights, particularly in relation to race. At Indiana State University (then Indiana State Teachers College) where he took his first collegiate job in 1946, racial segregation was well into 70 years of existence, supported by the enactment of Jim Crow legislation. Jim Crow legitimized inferior conditions for African Americans in contrast to whites. Thus, the disenfranchisement of African Americans despite their contributions the United States left them disadvantaged economically, educationally and socially.

The next year in 1947, Jackie Robinson broke the color line in major league baseball, and for a time fought resistance from select teammates, fans and much of the baseball establishment. John Wooden would witness inequity first hand when Clarence Walker, an African American player, was denied entry into the National Association of Intercollegiate Basketball Tournament (NAIB). Upon the decision, Wooden promptly turned down the invitation for his team to play in the tournament held in Kansas City.

With his team qualifying for the tournament again in 1948, Wooden refused participation again because of the still intact policy. His monumental stance, given the anti-progressive attitudes of the time, led to the tournament lifting their policy barring African Americans from competition. Walker became the first African American to participate in a national college basketball tournament [4].

Coach Wooden astutely paid attention to Black players and the complexities they faced during this time. Lew Alcindor, now known as Kareem Abdul-Jabbar, remembered Wooden's focus on his development as an individual while at UCLA. Kareem respected how Coach Wooden viewed him as a person because of his actions at the time:

Walking into a restaurant with Coach Wooden, I was greeted by a shout from a woman: "Oh look at the big, black freak." Sensing my shock at the slur, Coach 
Wooden did his best to diffuse the situation. Fortunately, I had enough maturity and self-confidence to refrain from responding, even though I was angered. It wasn't until years later that I realized how absolutely upset he was at the moment. He did such a great job of remaining calm and cool that while I was angry and wanted to be angry, he wanted to teach me that the most important thing I could do right then was to pity her for her ignorance. Coach's ability to work with me and understand how best to turn that moment into a classroom of sorts helped me move past a painful moment [5, p.113].

Wooden's concern for individuals considered matters of class, politics and religion. Despite rules that forbade it, he routinely fed players who lacked the money to travel to see their families during the holidays. Another player, Bill Walton, was a vocal opponent and protester of the Vietnam War. While Wooden disapproved of involving sports and politics, he supported Walton's right to free speech. As a mentor to Alcindor in his conversion from Catholicism to Islam, Wooden, a staunch Christian, provided a non-judgmental voice of stability. John Wooden epitomizes Mayes's [3] definition of archetype and is an appropriate model for exploring social justice dispositions in coaching education.

\section{TEACHING FOR JUSTICE THROUGH DEMOCRATIC EDUCATION}

Social justice is introduced through democratic education and enforced by those who respect the experiences of individuals. John Dewey felt that good education purposely benefits society and complements what students bring to the learning environment. This education arises from the interaction of two principles: continuity and interaction. Continuity assumes that each persons' experience will impact his or her future, regardless of the consequences. Interaction denotes the situational influence on one's experience. No experience has preordained value, thus a rewarding experience for one, could be an unfavorable experience for another [6].

Dewey believed that the value of the experience is judged on the effect that experience has on the individual in the current time, in the future, and the extent to which the individual later contributes to society. This theory of experience once obtained, allows for educators to organize curricula, instruction, and experiential opportunities that account for students' pasts increasing the likelihood of the student to positively contribute to society. Dewey's focus on experience, inclusiveness, and the non-hierarchal means of determining the value of experience, would help to establish an educational framework for the promotion of equity in the United States.

There are those who believe that social justice should be employed in a radical fashion. Henry Giroux [7] argues for a theory and practice of education that challenges existing institutions, with the aim of transforming society. Giroux sees the role of the teacher not as a deskilled intellectual, but as a risk-taking, critical agent who brings issues of equity, community, and social justice to the educational arena [7, 8]. These 'radical teachers' are responsible for addressing the content of curricula that replicates the perspectives of dominant groups. Further, he states that discussions of differences and inequities should be framed proactively. This is in opposition to cursory methods of teacher preparation that fail to prepare individuals to understand hegemony and the impact of it on oppressed groups and cultures.

For teachers to be critical agents that respect the democratic ideals of social justice, they must implement pedagogy, which is markedly different from the mere act of teaching [9]. McLaren holds that pedagogy integrates aspects of educational practice in the realities of 
what takes place in classrooms. Thus, curriculum content and design, classroom strategies, techniques, evaluation, purpose and methods, along with the views of the teacher, play a role in helping students frame their experiences and how they will eventually impact society.

Pedagogy for the social justice minded teacher follows a critical path and is dialectical in nature [8]. It is an open and questioning method of thinking that involves constant reflection back and forth on elements (i.e., part and whole, knowledge and action, process and product). As these elements are considered and negotiated, contradictions may be revealed that leads to new thinking and action [9]. Critical pedagogy creates spaces where students can discourse on issues related to inequality while receiving the tools to better themselves towards a more progressive and just society.

Teaching for social justice is a political endeavor. The constructivist nature of it is seen by some to be counterproductive to teaching civic ideals and blamed for instilling a general mistrust of systems of education [10,11]. Even among scholars who do work related to inequity, social justice in teacher education is noted as a well-intended idea that lacks a consistent theoretical framework. [12]. Literature on the assessment of social justice teaching is scarce. However, recent public attention to inequities in academic achievement, school resources, and allocation of funds for youth sport, have contributed to the recent focus on social justice in U.S. teacher programs.

\section{CONSTRUCTIVISM AND THE POTENTIAL IMPACT ON COACHING EDUCATION}

Constructivism espouses that knowledge is social in nature, with reality constructed by individuals as they observe, name, interpret and give meaning to the world they are surrounded by. Education that is constructivist in nature provides opportunities for teachers and students to question, consider, and invent knowledge. 'Understanding' in a constructivist world is contextualized and a primary part of an individual's learning process and goal. 'Knowledge', or facts and items to be remembered, plays a secondary role [14]. Constructivism requires constant reflection by educators as they examine their own personal engagements and attitudes, how they plan, what materials they use, classroom environments, and most importantly the needs of their students [15].

The overarching intention of the foundations course sought to introduce and inform students on principles related to social justice. Assignments included volunteer servicelearning opportunities, observations, a creation of a philosophy, a physical activity project on a country outside the United States, and a common reading.

\section{USING COMMON READINGS AND RESPONSE JOURNALING}

Common reading experiences foster conversation about controversial issues in many universities between students and faculty [15]. Schools in their use of common readings in introductory courses strive for intellectual discourse among peers and ultimately higher academic standards. Through the use of a coaching luminary as an archetype for social justice education, it was thought that aspiring coaches (AC's) could reflect uniquely on their thoughts, experiences and dispositions. The book Wooden on Leadership [16] was utilized for the foundations course as a common reading, in addition to a well-respected text in kinesiology.

Response journaling was chosen as a method to help encourage feedback from AC's throughout the course. Such journals involve students in recording "their personal reactions to, questions about and reflections on what they read, write, observe, listen to, discuss, do, and think" $[17,18]$. Particularly when weighing discourse on social justice, topics such as 
racism and class disparities can be politically charged. Further, these topics frequently elicit a range of experiences, such as shame, guilt, anger, or other negative feelings [18]. Thus, journals were used for this study to capture a range of reactions from participants in a less threatening fashion and compare dispositions of AC's throughout the foundations course.

As alluded to previously, coaches are highly involved in a range of tasks. They lead and manage multiple human elements routinely associated with high-performance [19]. Coaches require strong leadership to guide their teams [20]. Instruction and skill development for players undergoes implementation and assessment. Technical and tactical acumen is necessary. Emotional intelligence, or the 'soft skills' involved with motivation and inspiration, conflict management, and the ability to focus team members toward a common purpose is acknowledged as desirable attributes [19-21]. Planning and preparation are integral in providing successful outcomes. Issues pertaining to inequity and social justice may be unaccounted for or deemed as unnecessary for coaching professions. Constructivist education helps to combat this by providing the critical discourses needed to promote change.

\section{METHOD}

\section{PARTICIPANTS}

Forty-three students ( 27 male; 16 female) from foundations classes taught over a three year period (2008-2010) participated in the study at an urban Midwestern university in the United States. The course is composed of physical education candidates, with minor representation from students in additional kinesiology-related professions (exercise science, fitness studies) and core school subjects (math, science, history, English), who self-select into the course. Barring an exemption, the foundations course is a required prerequisite for moving into additional classes for physical education teacher education majors.

Under the curriculum plan of study, students take courses in planning for individuals with disabilities, cardiovascular and resistance training, teaching and analysis of motor skills, and principles of exercise and health. Civic engagement and service-learning opportunities are utilized in the training of future professionals in the program.

After approval of the study was granted by the institutional review board of the university, participants provided informed consent for data collection indicating their intent to take part in the study. All participants in the study were sophomores or juniors who identified themselves as aspiring coaches via a pre-survey. A stipulation of the research design was that data collected from students in the foundational courses could not be analyzed nor disseminated for a period of three years after the last class was researched. Further, all journal information and other identifying documents related to the research were to be destroyed after data was summarized, recorded and published. The study sought to answer: 1) where Wooden's impact was most evident in regard to assignments that aspiring coaches (AC's) completed in the foundations course; and 2) what aspects of Wooden did aspiring coaches find were most impactful in their thoughts on social justice.

\section{DATA COLLECTION}

Students were informed about the intent of the course during the first week in class and given a pre-survey of attitudes related to coaching, inequity, and ideals such as sportsmanship. The purpose of the response journal was explained. Over a 16-week period, classes were held twice a week for an hour and forty five minutes, with journals submitted biweekly. This provided six entries per participant or a total of 258 notations to review. Word-length for reflective journal responses averaged 753 words per submission. Each entry was typed and submitted through a secure online course management site. 


\section{DATA ANALYSIS}

Inductive analysis requires "immersion in the details and specifics of the data to discover important patterns, themes, and interrelationships; begins by exploring, then confirming, guided by analytical principles [22, p. 362]. For this study, inductive analysis: 1) condensed varied raw text data into a brief, summary format; 2) established clear links between the research objectives and the summary findings drawn from raw data and provides a level of transparency; and 3) assisted in the development of a theory about the underlying structure of experiences or processes evident in the text. The first review of AC's journals enlisted a research assistant to monitor potential biases in teacher-research and to help identify preliminary themes. Further systematic reading and coding of the journals allowed major themes to emerge in the study. The construction of themes for the study drew from the representation or specific reference to Wooden (i.e., name, quote, narrative) in AC's reflections.

\section{RESULTS}

Coach Wooden demonstrated a disciplined and self-initiated study of teaching along with research and observation $[23,24]$. He preplanned specific routines that maximized each minute of practice. Attention to detail in his basketball planning came from his observations of his previous coaches and his high school English teaching experience [25]. Wooden incorporated tactical strategies in basketball with the same urgency as mundane tasks which seemed to bear little significance.

Part of his widespread appeal is the simplicity in which he demonstrated to new players the proper manner of putting on their shoes and socks. Observations over a period of time showed him that players who had wrinkled socks often ended up with blisters. These blisters and the foot injuries from improperly tied shoes led in Wooden's view promoted bad habits [16].

Aspiring coaches' observed instruction in urban settings for physical activity and discoursed on specific instructional routines, methodologies and incidences. The diversity that AC's commented on spoke to recognizing the needs of those of a different language and issues of class. Raul stated:

I could tell that Coach Waters maintains complete control by the rules he posts and reminds students of. Many of his students are Spanish-speaking, so he has his rules in English and Spanish. When I interviewed him, he let me know that he enforces rules when students arrive in August, so that by October, things should be going to plan and they carry that on each year through elementary school.

Simon in the next passage connected his readings of Wooden to an incident in which he witnessed instruction during an American football practice:

....as I began to watch one of the line drills, I could see that the tacklers were having problems not getting their hands up fast enough to stop the defensive ends from collapsing the pocket. Evidently, they weren't doing too well with their footwork either.

After a few more reps that went about the same, an assistant coach stepped in. During his talking he gave some pointers saying things like "You guys have gotta get this down, we don't have time to do it all day. I have faith in you". It reminded me of one of the things Wooden said, "If you don't have the time to do it right, you won't have the time to do it over". 
One could imply that this dialogue is indicative of commentary replicated on many practice fields during the course of a sport season. There is nothing that speaks of inequity in these comments, as missed assignments happen and are addressed. However, further reading of Simon's entry detailed a perspective from the head coach:

Coach Davis asked me after practice if I had seen anything interesting in my visit. I told him about what I saw with the line coach and he smiled. He told me that most of the kids were from the local neighborhood and didn't have a lot of parental support or stability. He told me that most of the time, if you scream too much, players will shut down. They deal with a lot of insecurity and they don't have much to start with, so the main thing is getting them involved first, so they can gain confidence by the time they become adults.

The aforementioned passages provide a lens into urban schools that lack support. They are sites where English is spoken as a second language and self-efficacy is lacking [9]. Further, these are sites where mores of the dominant culture conflict with the realities of those who find structure and identity in sport participation.

Social transformation begins with the assumption that existing societal norms silence voices outside of the dominant culture [26]. In the first instance, consideration of rules that are listed bilingually is a critical and definable symbol of a group which impacts future mobility [27]. Freire held that educators provide the tools to help those from groups without power (in this case Spanish speaking individuals) successfully navigate mono-cultural worlds where instructional societal rules, laws, policies and practices often function against their interest [28]. Recognizing and incorporating students' cultural capital, via attention to language, culture, family interests and related considerations, empowers students. Thus instruction that is 'English Only' devalues the social reality and cultural background of students while perpetuating hegemony [7,9].

Numerous studies have linked structure and identity to sport participation among underrepresented populations in economically disadvantaged areas [e.g., 29-31]. Simon's observation illustrates a number of essential actions coaches must employ. The willingness to provide an atmosphere of success, empathy and high-expectations is needed to help those in disadvantaged areas meet their full potential.

Consider the ensuing narrative outside the spectrum of U.S. sport. Brother Colm O'Connell is an Irish Missionary at Saint Patrick's High School for Boys in the city of Iten, Kenya. The influence of O'Connell has helped Iten become world-renown as a training area for athletes looking to emulate Kenyan running success. O'Connell, "the Godfather of Kenyan running", had no intention of coaching when he arrived nearly 40 years ago. Despite his own perceived shortcomings, Coach O'Connell feels he is successful because of a consistent approach that takes into account the athlete's experience:

... "it's an attitude, an approach, it's the way you deal with an athlete. It's the environment in which you bring them that's what is important. It's not handing them a program or standing on the side with a whistle and a watch...I dumped all my western baggage when I came of how you think, how you want things to happen, what you believe in. I put all those aside and enter into the spirit of what it means in a rural village in the highlands of western Kenya." [32]

The greatest hurdles that Kenyan runners face are in the impoverished rural communities 
away from the training ground. For instance, O'Connell recounts the story of Sammy Wanjiru, who won the marathon at the Beijing Olympics, and suggests that the inability to handle instant fame impacted his death in May 2011. In his view, a holistic approach to training is a means by which to spot warning signs in athletes before trouble arises [33].

Different than John Wooden in his organizational methods, O'Connell is similar to Wooden in that he is committed to making them better persons. This speaks to Coach Wooden's remarkable legacy, drawing attention to one of his more notable maxims "Making greatness obtainable by all".

\section{ASPIRING COACHES NAVIGATE WOODEN'S PHILOSOPHY}

A maxim is a simple and memorable rule or guide for living thought to motivate individuals. They are subjective principles of action that can be associated with a 'folksy' or 'copy-book' approach to morality. Maxims inform personal philosophies and are the bedrock of belief and values that form the basis of personal character and wisdom [34].

The foundation for Wooden's maxims came from Joshua (his father) along with coaches Glenn Curtis and Piggy Lambert. In his early twenties, Wooden constructed the widely known Pyramid of Success, an extension of his own philosophy that would be refined over the rest of his life. Developing a philosophy provides "a distinctive organizing vision or a clear picture of why you are doing what you are doing that you can call up at points of crisis, crucial to maintaining personal sanity and morale" $[16, p .16]$. This vision requires educators to consider if their practices have an effect on students, learning outcomes and personal meanings that may result. In their reflections, many aspiring coaches such as Alan lauded John Wooden's efforts but mused if his approaches given UCLA's location and reputation as a progressive university were easier:

... with all of the craziness going on at the time, Coach Wooden showed a lot of character and strength. For a white coach to do what he did in recruiting Black players was unheard of. If I were in that situation, I would want my players to feel comfortable coming in, so I would find people with shared experiences. Wooden gained massive respect from everyone, but you could do that in California because it's historically known as a place more diverse and laid-back. I don't know if that would have been that easy if Wooden was in say, Kentucky or Purdue during the 60's.

While Jim Crow legislation fractured the southern United States and the civil rights efforts of African Americans, California's history of racism disenfranchised other groups with equal veracity. During the Great Depression of the late 1920's, more than four hundred thousand Mexicans and U.S. citizens of Mexican descent were corralled and sent back to Mexico. California Japanese in World War II were moved to internment camps due to fears regarding national security. The Watts Riots of 1965 framed inequality in economic and racial terms. Universities in California during the late 1980's began to address decades of campus incidents, with homophobia, mock slave auctions, sexist teachings, and anti-Semitism topping the list as the most egregious offenses [35].

As alluded to previously, Wooden encountered racial tensions in Kansas City (Walker) and at UCLA (Alcindor). It is plausible that similar attitudes toward his Black players existed among fan groups and teammates. The suggestion by Alan that California would have been an easier place to recruit Black players is at a cursory glance an astute comment. However, without a more thorough investigation of history, a facet of critical inquiry, Alan's 
observation is missing insight.

Wooden's actions are indicative of a person who stayed true to his beliefs. This does not mean that Alan should be condemned for his reflection. To the contrary, Alan is participating in liberatory pedagogy. Pedagogy of this nature challenges students to visualize different and life-changing perspectives. It aims to help students become critical thinkers of social justice issues and ultimately agents of change [28]. The hope is that Alan continues to recognize structures that could work to marginalize those he will coach while searching for truth and equality.

One memorable event in the search for truth arose in the 2009 class in a discussion of Serena Williams at the U.S. Open Tennis Tournament. Williams while trailing 6-4, 6-5 (1530), incurred a foot fault, resulting in two match points for her opponent Kim Clijsters. Williams gestured with her racquet to the lineswoman who had made the call and cursed at her, resulting in Williams being penalized a point for unsportsmanlike conduct.

This penalization along with a previous warning earlier in the match for racket abuse awarded Clijsters the match 6-4, 7-5. The following day, Williams was issued the maximum permissible on-site fine of $\$ 10,000$ (plus $\$ 500$ for racket abuse). After further investigation, the Grand Slam Committee in November of that year fined her \$175,000, instead of opting to suspend her from the 2010 U.S. Open or future Grand Slam events. Williams was placed on probation for two years and voiced displeasure over the decision, but did apologize.

Williams' episode was discussed in week 13 of the course during the midst of lectures on the impact of Title IX on sport. During one lecture, two contrasting videos were shown. The first video showed the aforementioned U.S. Open outburst by Serena Williams. Later, John McEnroe's memorable outburst at Wimbledon in 1981, known infamously as the "You Can Not Be Serious Match" was shown. McEnroe in the segment angrily disputed a line call where he felt a ball he had returned from his opponent, Tom Gullikson, was in bounds. A handful of aspiring coaches, chose to discourse in their journals on these videos of Williams and McEnroe, implying that there was a "double standard" still imposed on women that involved the additional element of race. The first extract below is from Jamilla, the second is from Ronald:

...the videos shown last week made me think of how far we still need to go. McEnroe has been making money off disrespecting authority for years. Serena if she did that all the time would lose money because she is a woman and she's Black. White athletes who get out of line have a longer leash.

Wooden probably isn't a big fan of these two. Really. Both of them are egomaniacs who think the world revolves around them. Like we talked about in class, young athletes look at these two as role models. If my daughter were like McEnroe, she probably wouldn't make it too far with that behavior unless she's lucky.

Despite significant progress made in regards to sport and gender inequities, instances such as this violate the principles of justice. While Williams demonstrated bad sportsmanship, she did apologize, admitting in a press conference after the match that she idolized John McEnroe. Upon hearing of this, McEnroe suggested that Williams apparently idolized him for the wrong reasons. Some students noted that Roger Federer at the same tournament lost composure during a match two days later, cursing at a line judge after a challenge by his opponent Juan Martin del Potro.

Curiously, Federer, arguably the greatest men's tennis player of all time and a 'gentleman' 
gave no apology and received little criticism for his behavior. Broadcaster Dick Enberg distinguished Federer's actions from Williams' by commenting that Federer's tirade was not venomous in intent. Truly, for instances where it still is acceptable for 'boys to be boys', the question of 'what can girls be?' remains unanswerable.

Zirin provides his opinion on the double standard when applying the gender flip test, asking if Williams were a man, would her behavior been met with similar outrage? [36]. Considering that tennis lore encourages and celebrates bombastic displays, men behaving badly is of no issue. Conversely, women are expected to be dignified and 'lady-like', subjected to their role in the tennis world as 'sweethearts' or 'petite darlings'. When players such as Serena Williams fail to fit into the predefined mold cast for them by media, society and tennis, they are promoted as the 'other' with the focus on their physical dominance and their desire to challenge authority.

Then there is the issue of race, class and acceptance. Williams, is an African American woman from Compton, California, one of the poorest high crime areas of the United States. Her rise through tennis with her sister Venus is well documented. Both have encountered racism by white parents as juniors, bigotry by fans at tournaments (e.g., Indian Wells Masters, 2001) and overtones by those in the sports world that question their work ethic.

Ironically, in a stadium named for Arthur Ashe, a tennis great and promoter of civil rights, Williams' next doubles match with her sister after the Clijsters incident included booing by fans and a questioning of her 'Americanness' at the U.S. Open in a manner most white players never encounter [36]. Serena's legacy as a great champion has followed a familiar script in American sport. If you are female, minority, or not part of the aristocracy, you are subject to a different set of scrutiny by those who frame sport (i.e., media) for the masses. Aspiring coaches would do well to consider these issues as athletes' performance could be impacted by complex situations away from competition and their own emotional states.

\section{CONCLUSION}

\section{TOWARDS A SOCIAL JUSTICE IN COACHING EDUCATION}

Coaching education must be proactive and plan accordingly for social transformation. In considering possibilities for preparatory programs, a discussion of a framework where democratic actions have the potential to be realized is appropriate. Giddens' structuration theory asserts that people create the structures in which they live, as much as structures constrain and provide them with opportunities for action [37, p. 324]. Therefore, coaching education programs that strategically plan for social action implement a curriculum that:

- $\quad$ places aspiring coaches in authentic settings where they are required to participate

- $\quad$ provides exposure to several archetypes or models that they could use as a starting point for their emerging philosophies and dispositions (i.e., Wooden)

- enables participants to recognize and critique what is presented to them in classes, practica/apprenticeship opportunities, and in society

- allows for participants to recognize their prior experiences, motivations for teaching, biases, apprehensions, and rationalizations for their choices

While structuration theory could be criticized as not broad and specific enough in scope [38], the apparent limitations gives room for individual programs to tailor their curricula as they deem necessary. Structuration theory as Giddens frames it allows for aspiring coaches and those who prepare them to participate in a cycle of educational practice. This cycle allows for praxis that actively involves participants in critical self-reflection, dialogue and 
action that examines inequities. Given the intent of the study, it is hoped that similar approaches will be utilized to help engage students in critical-democratic education that is needed for a diverse and global society.

The development of sophisticated dispositions regarding social justice requires a concerted effort by training programs to study forces that create inequity. Also, it is understood that issues related to social justice require an inherent risk of discourse on controversial topics along with the acknowledgement that answers found may be unsightly and uncompromising [39, p. 136]. Still, coaching education programs can benefit from being proactive in these matters, as this is an indispensable action that holds ramification for the perception of sport as an entity of change.

\section{REFERENCES}

1. Bell, L. A., Theoretical Foundations for Social Justice Education, in: Adams, M., Bell, L.A., and Griffin, P., eds., Teaching for Diversity and Social Justice, Routledge, New York, 2010, 21-26.

2. Richards, K. R. and Templin, T. J., Toward a Multidimensional Perspective on Teacher-Coach Role Conflict, Quest, 2012, 64(3), 164-176.

3. Mayes, C., Reflecting on the Archetypes of Teaching, Teaching Education, 1999, 10(2), 3-16.

4. Meyer, P., Standing Tall - Indiana State Remembers John Wooden, ISU Newsroom, Retrieved from http://www.indstate.edu/news/news.php?newsid=2289, 2010, June 7.

5. Wooden, J. and Jamison, S., Wooden: A Lifetime of Observations and Reflections On and Off the Court, McGraw-Hill, New York, 1997.

6. Dewey, J., Experience and Education, Macmillan, 1938.

7. Giroux, H., Pedagogy and the Politics of Hope: Theory, Culture and Schooling, Westview Press, Boulder, 1997.

8. Parkay, F. W., Anctil, E. and Hass, G., Curriculum Planning: A Contemporary Approach, $8^{\text {th }}$ edn., Allyn and Bacon, Boston, 2006.

9. McLaren, P., Life in Schools: An Introduction to Critical Pedagogy in the Foundations of Education, $5^{\text {th }}$ edn., Pearson Education, Boston, 2007.

10. Hartocollis, A., Who Needs Education Schools?, The New York Times, 2005, July 31.

11. Ravitch, D., Left Back: A Century of Battles over School Reform, Simon and Schuster, New York, 2000.

12. Grant, C. A. and Agosto, V., Teacher Capacity and Social Justice in Teacher Education, in: Cochran-Smith, M., Feiman-Nemser, S., Demers, K.E. and McIntyre, J., eds., Handbook of Research on Teacher Education: Enduring Questions and Changing Contexts, $3^{\text {rd }}$ edn., Routledge, New York, 2008, 175-200.

13. Sparks, D., A Paradigm Shift in Staff Development, Journal of Staff Development, 1994, 15(4), 25-29.

14. Wiggins, G. and McTighe, J., Understanding by Design, Association for Supervision and Curriculum Development, Alexandria, 1998.

15. Thorne, A., Beach Books: What do Colleges Want Students to Read Outside Class?, National Association of Scholars, Retrieved from: http://www.nas.org/polArticles.cfm, doctype_code5Article\&doc_id51337\&. 2010, 2013, June 18.

16. Wooden, J. and Jamison, S., Wooden on Leadership, McGraw-Hill, New York, 2005.

17. Parsons, L., Response Journals Revisited, Stenhouse Publishers, Maine, 2001.

18. Mio, J. S. and Barker-Hackett, L., Reaction Papers and Journal Writing as Techniques for Assessing Resistance in Multicultural Courses, Journal of Multicultural Counseling and Development, 2003, 31, 1219.

19. Chan, J. T. and Mallett, C. J., The Value of Emotional Intelligence for High Performance Coaching, International Journal of Sports Science and Coaching, 2011, 6(3), 315-328.

20. Mallett, C. J., High Performance Coaches' Careers and Communities, in: Lyle, J. and Cushion, C., eds., 
Sports Coaching: Professionalism and Practice, Elsevier Science Publishers, London, 2010, 119-133.

21. Cushion, C.J., Modeling the Complexity of the Coaching Process, International Journal of Sports Science and Coaching, 2007, 2(4), 395-401.

22. Johnson, R. B. and Christensen, L. B., Educational Research: Quantitative, Qualitative, and Mixed Approaches, $3^{\text {rd }}$ edn., Allyn and Bacon, Boston, 2004.

23. Gallimore, R. and Tharp, R., What a Coach Can Teach A Teacher 1975-2004: Reflections and Reanalysis of John Wooden's Teaching Practices, The Sport Psychologist, 2004, 18(2), 119-137.

24. Gilbert, W., The Passing of a Legend: Coach John Wooden, International Journal of Sports Science and Coaching, 2010, 5, 339-342.

25. Ermeling, B., Improving Teaching through Continuous Learning: The Inquiry Process John Wooden Used to Become Coach of the Century, Quest, 2012, 64(3), 197-208.

26. Bercaw, L. A. and Stooksberry, L. M., Teacher Education, Critical Pedagogy and Standards, Essays in Education, 2004, Retrieved 9/13/13 at http://www.usca.edu/essays/vol122004/Bercaw.

27. Culp, B. and Schmidlein, R., Preparing PETE Programs for Culturally and Linguistically Diverse Learners, Strategies, 2012, 25(7), 11-14.

28. Freire, P., Pedagogy of the Oppressed, Continuum, New York, 1993.

29. Falcous, M. and McLeod, C., Anyone for Tennis? Sport, Class and Status in New Zealand, New Zealand Sociology, 2012, 27(1), 13-30.

30. Bimper, A. Y., Ethnic Identity and Task Value Placed on Sport by African American Youth, PhD Thesis, Purdue University, 2009.

31. Johnson, T. S. and Migliaccio, T. A., The Social Construction of An Athlete: African American Boys' Experience in Sport, Western Journal of Black Studies, 2009, 33(2), 98-109.

32. Drazen, J., Irish Missionary Behind Kenya's Running Success, Reuters, 2012, July 19.

33. Kiberenge, K. and Cooper, C., The Irish Priest Who Made Running a Religion in Kenya, The Independent, 2012, August 7.

34. Dalton, J. C. and Trexler, A., Nuggets of Practical Wisdom, New Directions for Student Services, 2002, 98 , 95-100.

35. Delgado, R. and Stefancic, J., California's Racial History and Constitutional Rationales for Race-Conscious Decision Making in Higher Education., UCLA Law Review, 2000, 47, 1521.

36. Zirin, D., Double Standard for Serena Williams, The Nation, 2009, September, 28.

37. Kruger, T. and Cherednichenko, B., Social Justice and Teacher Education: Re-Defining the Curriculum, International Journal of Learning, 2006, 12(7), 321-332.

38. Stones, R., Structuration Theory, Palgrave Macmillan, New York, 2005.

39. Culp, B., The Strategic Application and Assessment of Social Justice in PETE Programs: A Primer, Physical Educator, 2011, 68(3), 130-139. 
Copyright of International Journal of Sports Science \& Coaching is the property of MultiScience Publishing Co Ltd and its content may not be copied or emailed to multiple sites or posted to a listserv without the copyright holder's express written permission. However, users may print, download, or email articles for individual use. 